Fecha de entrega: 17 de mayo de 2010

Fecha de aprobación: 30 de junio de 2010

\title{
DEVENIR EXTRANJERO: UNA LECTURA POSITIVA DEL HAY EN LÉVINAS*
}

\section{FOREIGNER BECOMING: A POSITIVE READING OF AVAILABILITY IN LÉVINAS.}

\author{
Francisco Javier Parra Bernal ${ }^{* *}$
}

\section{Resumen}

Una lectura positiva del Ser en el sentido levinasiano es lo mismo que abrir el espacio para preguntar por un sentido ético del Hay. Esta posibilidad se puede contemplar si pasamos de la designación negativa de la poesía, cuya función parece limitarse a denunciar y deshacer la totalidad a la que somete la ontología experimentando la noche y el horror, a su anunciación de una tierra inhabitable y cuya única ruptura radica en un decir más allá del habla de lo neutro. Para esto, la poesía debe ella misma salir hacia la intemperie, recorrer el camino mismo del arte, hacia el encuentro con el otro.

\section{Palabras clave}

Hay, alteridad, poesía, neutro, extranjero, decir.

\begin{abstract}
A positive reading of being in the Lévinasian sense is the same thing that giving room to ask for an ethical sense of the "there is". This possibility can be contemplated if we move from the negative description of poetry, whose function seems to limit to denouncing and undoing the totality to which it submits the ontology experimenting the night and the horror, to its Annunciation of an uninhabitable land and whose only break takes root in one saying beyond the speech of the neutral thing. To this end poetry go herself must outdoors, cross the road itself of art, towards the meeting with the other.
\end{abstract}

\section{Keywords}

Otherness, poetry, neutral, foreign, saying.

Artículo de investigación para este número monográfico.

** $\quad$ Filósofo de la Universidad de Antioquia 
Sólo queda entonces decir que el encuentro entre la ética y la estética radica en el asunto del Decir.

Daniel Charles (2005)

1.

El decir original es el delirio.

Lévinas (1967, p. 236)

El existir sin existentes, el Hay, es designado por Lévinas de diferentes maneras: el ser sin existentes, el arte, el insomnio. Pero, más que simples metáforas de lo mismo, constituyen una concentración de la sombra de la realidad que se agrieta con la mirada del otro. La luz impersonal de lo neutro sólo se deshace cuando se hace urgente lo imposible: salir de ella. Así, la verdadera necesidad de ruptura sólo urge en el ahogo de lo ontológico, en la plenitud del ser. Otras formas clásicas de romper con el ser, de trascenderlo, configuran en esa ruptura el mismo camino por las que quedan enclavadas a la estructura de lo ontológico, pues no asumen el ser en toda su gravedad, el hecho brutal de la existencia y no del existente (Lévinas, 2000a, p. 75). Una verdadera ruptura sólo acontece en la "experiencia" de esta noción del ser sin existentes, sin objetos que la oculten ni mundos que la disfracen. Para ello, es necesario experimentar el fin del mundo en su propia infinición.

Sólo la experiencia de la noche (suponiendo que así se le pueda llamar a una relación que no conlleva a la síntesis de lo lumínico), de la noche insómnica puede indicar tal necesidad de evasión en su auténtica dimensión. Y no se trata aquí de la noche que sirve de tránsito entre días, sino de aquella que se encuentra separada de toda intencionalidad o referencia más allá de ella misma: se trata de la noche sin referencia alguna, olvidada en los primeros rayos del sol. De este modo, la urgencia de la ruptura sólo acontece en la comprensión de dicha "necesidad" que no se apoya en ninguna deficiencia, sino en la plenitud de la existencia, en la imposibilidad de suspensión o de vacío. La necesidad de evasión, el deseo de lo otro (y no de las invenciones de la alteridad de la metafísica llegada a su fin) ocurren en el Hay, expresión de toda la gravedad del ser. Si se puede poner en términos de la reducción fenomenológica, se trataría de encontrar la epojé allí donde lo reducido retorna sin cesar sobre la acción de la reducción, donde ya es imposible llevarla a cabo, excepto por la interrupción "siempre demasiado pronta", sin espera ni asunción, de la muerte.

El Hay puede ser expresado entonces como la imposibilidad misma de habitación, de morada. Cuando las cosas del mundo se imponen en su pura materialidad desbordando su condición de objetos, cuando el mundo deja de ser espacio de un sujeto que puede y que posee, allí acontece la auténtica apatridia, el exilio fundamental. Esta ruptura con el ser como verdad y como morada a través del ily $a$ apunta críticamente a las diversas maneras de asumir el principio ontológico y a sus distintos presupuestos. La conceptualización, la comprensión de la relación del sujeto y el mundo como representación, la sensibilidad entendida como dato sensible reducido a la configuración subjetiva son momentos que implican la libertad antes que la justicia, la ontología previa a la metafísica. Al contrario de todo esto, el ser desaloja al sujeto de sí mismo, de lo de sí, hacia un afuera sin aprehensión posible. El camino de dichas condiciones ontológicas, la transformación de la casa del ser hacia un desierto sin topos, se le puede designar como el exotismo del arte. A través de la expresión radical de la estética, el sujeto transita esa brecha, ese abismo, ese entretiempo entre el ser y el Hay. 
Hemos pasado a otra de las figuras del Hay, esta vez bajo la forma del exotismo del arte. Ya desde Heidegger se conoce que la pregunta por el ser debe atravesar la historia de la metafísica para experimentar su fin, esto es, penetrar en la historia de un logos del ser confundido con el ente, la ontoteología; debe soportar el olvido del ser como constitutivo de su propia historia, su ausencia como principio y como revelación, lo cual se traduce entonces en otra experiencia del lenguaje. Parafraseando a Lévinas, se trata de enfrentar la dificultad de decir el ser con un lenguaje que recae en el ente, en el sustantivo. Tal expresión vuelve constantemente sobre su propio círculo, sin salir de él, cuidando de sí, comprendiéndose y comprendiendo el ser, diciéndolo en su ausencia. Esta habla que guarda al ser en su verbalidad es la poesía $^{1}$. Guardiana, la poesía dice su retirada, consciente de la expulsión del hombre del elemento del pensamiento y diciendo esta misma expulsión (y por ello mismo, retornando de esa misma expulsión). La metafísica de la presencia había desenlazado al sujeto de su relación con el ser en cuanto ser, entregándole un habla que olvidaba aquello a lo que desde siempre pertenecía, la lejanía ontológica. "El alma exiliada aquí abajo, que Platón transmite al pensamiento metafísico, testimonia ya el olvido del ser" (Lévinas, 1993, p. 91). El exilio sería la inautenticidad por excelencia, revelado por ejemplo en la intención teorética de la filosofía. La poesía en cambio designa con esta indicación una habitación, una morada, una pertenencia destinal y esencial al hombre. Pastor del ser, la libertad del hombre radicaría entonces en una obediencia esencial a lo neutro en el que encontraría de nuevo su

$1 \quad$ El lenguaje es la casa del ser. En su morada habita el hombre. Los pensadores y poetas son los guardianes de esa morada. Su guarda consiste en llevar a cabo la manifestación del ser, en la medida en que, mediante su decir, ellos la llevan al lenguaje y allí la custodian" (Heidegger, 2000, p. 259). verdad, su desocultamiento. La poesía aquí salva la ontología.

Pero sería necesario atender aquí nuevamente a Lévinas, y retomar la urgencia planteada a partir del ahogo del ser, metafísica que no va hacia la verdad ontológica, sino que intenta desfigurarla y salir de ella. De este modo, preguntarse si "¿acaso la noción de sujeto refleja únicamente lo que Heidegger denomina la historia del ser y cuyo olvido metafísico esboza las épocas en la historia de la filosofía?”, si “¿señala la crisis de la interioridad el fin de ese extrañamiento de la excepción o el exilio del sujeto y el hombre?" (Lévinas, 1993, p. 91). En correspondencia a la evasión, se impone la pregunta por un exilio aún más auténtico que toda pertenencia o habitación en lo neutro, una separación cuya realidad radica en no fusionarse de modo alguno en los paisajes ontológicos. Y además, retomando lo exótico del arte, podríamos igualmente preguntar si acaso la poesía no puede hablar de otro modo que como guardiana, mostrando la ausencia de lugar y de patria, señalando el nomadismo esencial del hombre (Lévinas, 1975 , p. 24). ¿En este sentido, hay lugar en la ética para la poesía?

Pero es necesario ahondar en la cuestión del exilio, en el cuestionamiento del ser. Lo que la interioridad del ser y el "retorno al elemento del pensamiento" indican es más bien el fallido intento de tal separación. Entonces, como se mostró anteriormente, esto implica la urgencia de otro modo. Si cierta interpretación de la poesía dice tal pertenencia sagrada, es necesario invertir la investidura del arte en función de indicar el desarraigo esencial al que conlleva esta plenitud del ser. Lévinas retoma en este sentido la obra de Blanchot, de Celan y el Antiguo Testamento para deshacer este lenguaje de la morada del ser. 
2.

Ese afuera insólito no es un paisaje otro.

Más allá de lo simplemente extraño del arte y de la abertura al ser del ente, el poema da un paso más. Lo extraño es el extranjero o el prójimo.

Lévinas (2003)

Efectivamente, el arte, en especial el contemporáneo, por su radical señalamiento de la materia que se impone sin perspectiva posible, "muestra", jalona hacia la experiencia de esa exterioridad del ser. El exotismo del arte modifica su pretensión de lo bello, de la unidad de sentido y, en suma, del ritmo, hacia una materialidad singular más fundamental: el Hay. El arte se vuelca hacia una crítica del arte, hacia su autodeconstrucción, como una experiencia más esencial que desteje en la noche su servidumbre a una filosofía de la totalidad (pero que lo mismo, vuelve a tejerla en el día, hasta que descubran su engaño).

\section{Así, tanto en el Exotismo como en La realidad} y su sombra, el arte marca la separación de las cosas del mundo. Las expulsa de la totalidad referencial que permite la comprensión y la aprehensión: su disponibilidad para un sujeto que puede y que posee. El sentido exótico del arte apunta hacia la experiencia misma del Hay. Designación de una imposible distancia frente a los objetos, ya no ofrecidos a través de lo sensible, sino más bien marcados con el signo de la radical extrañeza. Lo sensible que se daba como dato, reaparece detrás de toda objetivación, imponiéndose como enigma que no se acota en marcos de referencia. En el arte pictórico, precisamente el marco del cuadro presenta una porción del universo sin contenerla, desbordando los márgenes como los colores de Dufy: "La limitación del cuadro, que depende de la necesidad material de producir algo limitado, proporciona, gracias a las líneas abstractas y brutales de este límite, una condición positiva a la estética" (Lévinas, 2000b, p. 72). Los límites son al mismo tiempo la colocación de la obra en este mundo y el medio por el cual deshace el orden de la interioridad.

La invasión del afuera realiza una doble ruptura. Por un lado, rompe la finalidad perceptiva de la multiplicidad sensible, interrumpe el camino hacia la intencionalidad objetiva; esto es, muestra el elongamiento, el entretiempo, la suspensión del noema antes de su cristalización, y al mismo tiempo le niega a lo estético la autenticidad de un destino objetivo. Lévinas recupera, por tanto, la noción de aisthesis y todo su peso material, desbordando la psicología kantiana y hasta la hermenéutica heideggeriana, inversión radical de la Befindlichkeit: ya no remite a un encontrar-se, sino precisamente a esta imposibilidad de lugar. El arte no sólo ahoga y hace estallar a los objetos como útiles, sino que desaloja al yo de su propiedad, lo expulsa de sí mismo hacia la impersonalidad del elemento. En otras palabras, acontece allí el ser puro, el ritmo sin adherencia a ningún ente.

La característica del ritmo no se acopla ya a ninguna síntesis objetiva y se radica en que la síntesis a la que es susceptible no corresponde ya a ningún orden objetivo (Lévinas, 2000b, p. 71). Es por esto que el ritmo y la música constituyen aquello a partir de lo cual se debe comprender la imagen del arte, pues revela la separación radical del mundo del ente. "La sensación no es un residuo de la percepción, tiene una función propia: el dominio que ejerce sobre nosotros la imagen; una función de ritmo" (Lévinas, 2006, p. 124). Sin embargo, la musicalidad anónima del ritmo parece aún salvar al sujeto de su identidad, dándole abrigo, acogiéndolo como aquel que al escuchar una obra musical en realidad se está conteniendo de bailar. Como una marioneta (y el arte, como recordarán dice Celan, es una figura de teatro de marionetas, de cinco pies 
yámbicos), el yo en el ritmo del arte se retira de sí en un sueño despierto. Sin completo exilio, el arte aún constituye, "en el mundo de la iniciativa y de la responsabilidad, una dimensión de evasión" (Lévinas, 2006, p. 137). El hecho esencial de un yo que permanece enclavado en sí, soportando el universo entero, la oscuridad del ser entraría en el ritmo como relajamiento de dicha carga inevitable y por ello inasumible. El arte, si bien "aporta al mundo la oscuridad de un fatum", aporta igualmente "la irresponsabilidad que halaga como la levedad y la gracia" (Lévinas, 2006, p. 137). Es el yo del gozo, en el cual no nos vamos a detener.

Por esto, más allá de la música y del arte, en el camino hacia su propio fin, reaparece la exigencia del Hay bajo la exigencia moderna. La expresión de la imposibilidad de síntesis no se hace expresa en el arte que busca lo ideal, aún relajo del sujeto, sino en la noche hacia la que dirige el arte que deshace hasta sus propias pretensiones. Es necesario transitar el camino del arte para que en su extremo lleve precisamente al terreno de toda imposibilidad, a la desmusicalización de la vigilia. No resulta casual, en este sentido, que la alusión explícita a Blanchot en De la existencia al existente se realice después del exotismo, en la saturación verdadera del ser.

El exotismo de la estética, en la cual encuentra ella su sentido más significativo, desencubre al ser para revelarlo en su propia imposibilidad de verdad. Dice su verbalidad misma, su corriente anónima, temporalidad inasumible por ninguna narración o tematización. Experiencia del desastre sin promesa de verdad, permanencía en la medianoche sin esperanza, el arte a través de la poesía y el canto "mantiene en vigilia constantemente a los verbos a punto de caer en sustantivos" (Lévinas, 1987, p. 91). Y esto se realiza sin aplazamientos ni excusas en la locura sin ritmo del decir poético. Es necesario expe- rimentar el extremo de esta arritmia, de esta apatridia, para encontrar allí la auténtica condición exótica del arte: la noche insómnica. ¿Estaremos así llegando a las dicciones en bloque de la poesía contemporánea, ritmo del verbo, es decir, ausencia de ritmo, entretiempo y anfibología?

La obra de arte permanece fundamentalmente infinita, sin acabamiento, deshaciendo toda determinación. "Ella obedece a la ley de la esencia como temporalización del tiempo o diastasis de lo idéntico o verbalidad del verbo" (Lévinas, 1987, p. 91), tal como en Nomos Alpha de Xenakis, el violonchelo violoncheliza, como el rojo rojea o la a aea. Dice el ser, pero sólo lo nombra en la vigilia.

Retomando la pregunta de si la poesía puede decir el exilio del yo, autenticidad de una separación que hace necesaria otra metafísica sin obedecer al fin de la metafísica de los ídolos, podríamos decir aquí entonces que más bien ese exilio es la condición misma de la poesía. Será necesario seguir de la mano de Blanchot.

\section{3.}

Búsqueda dedicándose en poema al otro; un canto sube en el dar,

en el uno-para-el-otro, en la significación misma de la significación.

Lévinas (2003)

Los hombres se buscan en su condición de extranjeros.

Lévinas (1993)

La confrontación que hace Lévinas entre la noche blanchotiana y la cuaternidad heideggeriana abre un sentido: la posibilidad de pasar del espacio literario al espacio ético. La poesía ya no se muestra guardiana del ser, palabra dirigida al paisaje ontológico, sino 
pensamiento arquitectónico del exilio, del nomadismo. Su enunciación ética ya no está condicionada por la designación y descenso al subsuelo nocturno, sino por la exposición de todo refugio y el desapego de esta tierra como en algo que ya no sólo no le pertenece al sujeto, sino que le pertenece al Otro. La profundidad en la extrema medianoche del espacio arrítmico, del ser sin interrupciones ni fisuras, expresa en sí la condición del exilio, declarado o designado por el Otro: "La tierra no se venderá sin derecho a retracto, porque es mía, y en lo mío sois emigrantes y criados" (Levítico, 25, 23; Lévinas, 1993, p. 82).

En palabras de Lévinas, el arte según Blanchot, a través de la negra luz, muestra la esencia de exilio de nuestra morada, devuelve a "las maravillas de nuestra arquitectura, su función de cabañas en el desierto" (Lévinas, 1974, p. 23). De ahí, que se diga entonces: "Paz a las cabañas, guerra a los castillos". Este decir de Büchner es una sentencia ética, una poesía del exilio que desde luego no entiende la paz como quietud y descanso. Incluso, se podría decir, toca a la cabaña de Heidegger, Todtnauberg, para deshacer la physis en desierto mineral, enterrados bajo la montaña, y no mirando desde ella.

El exilio fundamental remite al rostro del otro, a la condición de rehén. La extranjería se impone en la palabra desconocida, en la voz que se expone: palabra trascendente que es ofrecimiento del yo que sólo se tiene a sí para sostenerse. La exterioridad es espacio de proximidad entre los hombres, espacio de ruptura sin continuidad, sin luz que ponga en conjunto los términos absueltos: "El uno y el otro, separados por el intervalo de la diferencia o por el entretiempo que no anula la no-indiferencia de la responsabilidad, no están obligados a reunirse dentro de la sincronía de una estructura o a comprimirse en un estado del alma" (Lévinas, 1987, p. 216). Entretiempo, palabra utilizada para hablar de la imagen del arte, constituye aquí el intervalo de proximidad, bajo la condición, ya expuesta, de no absorberse nuevamente en sincronía o en ritmo.

Apatridia, "eco del decir permanente de la biblia: la condición o incondición de extranjeros y esclavos en Egipto acerca al hombre al prójimo" (Lévinas, 1993, p. 82). Una moral de esclavos descifrada por la poesía ausente de la ciudad o del paisaje heideggeriano. Y en ese sentido, el lugar es el desierto en el cual la poesía como decir del Hay se hace constitutivo de la ética. A través de Blanchot, quien se rehúsa explícitamente a la ética (“dejemos a Dios, palabra demasiado imponente"), la poesía transita errabunda hasta el extremo de lo ontológico para alcanzar la penumbra del profeta, del peregrino.

¿Y cómo atravesar este desierto literario? La relación con el Otro acontece, como se plantea en Totalidad e infinito, ante la mirada del hambriento, del exiliado: el yo es invocación y respuesta a ese otro. Sin morada, sin patria, en el suelo nocturno del Hay, el decir es plegaria y signo de exposición. La poesía presenta la miseria humana, atravesando la noche del Hay cuya impersonalidad entorpece toda donación de mundo, haciéndose montaña de piedra que hay que atravesar.

Este rostro de miseria no lo comprendo, no lo absorbo en la totalidad de un contexto, ni lo considero como igual. Tampoco me abstraigo de mi condición ni renuncio a mi subjetividad, ya que me encuentro en la noche del ser, revelación de la identidad inaplazable del yo. Considerar el postergamiento de mi identidad de elegido, la concepción de la miseria como falta o fallo, retornaría inevitablemente a la lógica de la verdad del ser, a la metafísica ya fallida. El yo debe permanecer como absoluto, en su soledad insoportable sin ausencia de lucidez, sin romper con su punto de partida, sin deshacer los vínculos con la 
sombra afirmándose en su designación de soportante; mientras que lo Otro lo designa en su unicidad, llamándolo a responder: crítica siempre previa al dogmatismo.

El espacio de proximidad es el del entretiempo, hormigueo de puntos que no reivinidican un yo-puedo, un yo-poseo, sino que lo invierte en pura pasividad: "la proximidad no es un estado, un reposo, sino que es precisamente inquietud, no-lugar, fuera del lugar del reposo que perturba la calma de la no-localización del ser que se torna reposo en un lugar, por tanto, siempre proximidad de un modo insuficiente, como un apretón" (Lévinas, 1987, p. 142). Un apretón de manos, como definía Celan al poema en su carta a Hans Bender ( Lévinas, 2003).

En la obligación de responder, ese rostro del hambre es el rostro del Dios invisible. La revelación de su altura monoteísta concierne y estrecha hasta devenir delirio del decir, locura del amor expresada en el Fedro. "El poeta, ante la "afluencia eterna del afuera", ¿no escucha la voz que llama por fuera del mundo heideggeriano?" (Lévinas, 1975, p. 25). Esta escucha sólo es posible si la poesía ha desandado el camino del arte, para exponerse a sí misma como extranjera, como devenir puro sólo concebible en aquel que soporta sin asumir el ser sin existentes. Ella rompe con el ritmo de la imagen del arte para deshacer sílaba por sílaba el techo del lenguaje, y elevarse en el exilio hacia allí donde escuchamos la voz de Dios, trascendente casi hasta confundirse con el Hay.

4.

El Huésped

Mucho antes de anochecer

Entra en tu casa quien con lo oscuro el saludo cruzó.

Mucho antes de amanecer despierta y atiza, antes de irse, un sueño un sueno resonante de pasos: le oyes recorrer las lejanías y hacia allí lanzas tu alma.

Paul Celan (2000)

Filosofar, ¿es descifrar una escritura oculta en un palimpsesto?

Lévinas (1993)

Finalmente, es la poesía misma la que se expone en su condición de Decir. Decir, y no dicho, y sólo así genera el movimiento inacabado de la ruptura del Hay. No podría nunca salir de él porque ello constituiría inmediatamente la amenaza de otra luz, y por ello debe andar con su propia sombra: el Hay es la vigilia sin lugar. Pero también Decir y no Dicho, porque el poeta, al atravesar el camino del arte del mismo modo como recorre la ontología hasta la noche del Hay, desemboca en el triunfo sobre las estatuas sin vida, en la fecundidad de la obra que no se asimila como su producto. La fecundidad de la obra sólo proviene de un yo que ya no tiene poder sobre sí, que es pura pasividad. La paternidad no es posesión, es la conversión del yo en lo diferente. La poesía, como lo hemos expuesto, no produce entes muertos, pues su decir dice su propio decir, lo expone como palabra de trascendencia.

En este sentido, la vida de la obra es responsabilidad también del crítico. En La realidad y su sombra es la crítica filosófica la que devuelve al arte y al poeta de vuelta a la ciudad. Se comporta como ante eso otro que lo invoca en la responsabilidad de quien interpreta, lo cuestiona en su propia condición de intérprete, para hacerlo alguien que responde. Los poemas, en este sentido, son un diálogo desesperado (Celan, 2002, p. 501). Responsable hasta de la existencia del poema, la exégesis poética camina el mismo camino del poema, hacia el exilio fuera de 
contexto, en relación con un tú a quien no se interpreta desde la simpatía. Así lo plantea en el texto de 1948: esta exégesis poética debe corresponder "a la perspectiva de la relación con el otro, el prójimo, sin el cual el ser no podría ser dicho en su realidad, esto es, en su tiempo" (Lévinas, 2006, p. 140).

La crítica filosófica recibe al mismo tiempo la crítica del poema, que le habla en otro lenguaje. Por ello, esas sorprendentes vecindades de palabras que explotan su sentido como bloques separados no podrían ser acogidas dentro de una visión de la unidad de sentido. Salir propiamente de la hermenéutica de la totalidad, hacia un espacio de proximidad que pone al crítico en relación con el prójimo, con su decir diacrónico y que me inviste de responsabilidad. En su poema "Grisblanco", el canto de los pozos es apreciado desde la separacion y la multiplicidad: "Una oreja, cercenada, escucha. Un ojo, cortado en tiras, aprecia todo esto en lo justo" (Celan, 2002, p. 58). El ojo del que lee camina por la dispersión de los versos y las palabras, sin unificarlas en el continuo de sentido.

Gadamer en Poema y diálogo plantea muy bien, respecto de la poesía de Celan, la ruptura que esta posibilidad ética del poema quiere llevar a cabo: "Esa dicción en bloque, en la que las palabras aisladas que suscitan determinadas representaciones, se encuentran unas al lado de otras, no significa que dichas palabras no puedan fundirse en una unidad de sentido. Lograr esta unidad, sin embargo, es una exigencia cuyo cumplimiento queda al arbitrio del lector" (Gadamer, 1993, p. 118). Llevar el poema que con su lenguaje de alteridad rompe la unidad de sentido a la sincronía del horizonte de interpretación es permanecer en el terreno ontologizante. Más que el arbitrio del lector, se trata de la atención del mismo, aquella que Benjamín llama "la oración natural del alma". Al contrario de Gadamer, podríamos aludir a la "receptividad extrema, extrema donación también. Atención, modo de conciencia sin distracción, esto es, sin poder de evasión por obscuros subterráneos. Plena luz proyectada no para ver las ideas, sino para impedir la fuga. Sentido primero del insomnio que es la conciencia, rectitud de la responsabilidad, anterior a todo aparecer de formas, de imágenes, de cosas" (Lévinas, 2003).

La importancia del Hay, de esa vigilia, se constituye finalmente como el sinsentido tras el sentido, la refutación a todo dicho, de toda interpretación aprehensora. Es la posibilidad crítica como amenaza constante del retorno de la ontología y el olvido del otro. Asimismo lo retoma Ricoeur cuando plantea la repetición de la ontología: “ ¿Y si no hubiese sentido? ¿Y si la ignorancia y el olvido fuesen la última palabra? Miedo a morir u horror del Hay, es lo mismo... para lo cual no hay otra respuesta -en ausencia de garantía-que la exposición, la pasividad del soportar" (Ricoeur, 1999, p. 32). Acaso es en este punto donde, como indica Lévinas en De Dios que viene a la idea, la trascendencia de Dios se llega a confundir con el Hay. El sentido más allá del sinsentido no retorna a la verdad pre-insómnica.

\section{5.}

Mucho antes que el amanecer, la poesía se nos adelanta a veces, "ella también quema nuestras etapas" (Celan, 2002, p. 504). La lengua que es ya responsabilidad sin consentimiento no se dirige a la totalidad de lo neutro, antes intenta experimentar su propio ahogo para salir de ella. Y sale insertándose en ella como mendigante, sin habitar, insertándose en el habla que habla del habla como extranjero que se expone en su decir sin receptor esperado. Adelantándose a toda apercepción, expone a todo aquel que la escucha. Mendigo que es altura de Dios, cuya condición es revelar la estrechez del ser propia de un 
sujeto-rehén. A este respecto, dice Celan en su poema "En las estrías":

En las estrías/ de la moneda del cielo en la ranura de la puerta/ prensas tu la palabra de la que yo rodé/ cuando con temblorosos puños/ desmonte el tejado sobre nosotros/ pizarra a pizarra/ sílaba a sílaba/ por amor al brillo/ de cobre de la escudilla/ de mendigo allí/ arriba (Celan, 2002, p. 161).

La caída de la cubierta en la casa del ser parece una relación tardía con la palabra de un tú. Categorías buberianas resaltadas por Lévinas que se prefieren a las descendidas del misterioso Schwarzwald sobre Hölderlin, Trakl y Rilke, "para mostrar la poesía abriendo el mundo, el lugar entre tierra y cielo" (Lévinas, 2003).

Un tú tardío, de otro tiempo, que me designa en mi responsabilidad. Por ello, el espacio que separa se hace insondable, liturgia, obra o movimiento del mismo que no retorna jamás al mismo. Obra que es donación de mi propia donación, entrega sin gratitud, gasto sin pérdida de sí. El intervalo de proximidad deshace así todo intento de continuidad y homogeneidad, ya que es relación sin relación, diacronía de tiempos. En eso radica la vida del poema, en ser entrega sin retorno ni sentido, exposición en la propia experiencia de la donación. Sin retorno, en una diacronía inasumible e irreductible a la no-presencia de lo neutro, este llamado de responsabilidad es memoria. No se trataría de una recuperación del pasado que salva el fatum del pasado en el control lumínico y apropiador del presente. Esta memoria es trascendencia y relación con la altura a través del negro rayo que palpa hacia arriba la invisibilidad de lo más alto.

Trascendencia que no radica en una fusión o en una entrega a otro que alivianaría toda responsabilidad. Este movimiento deja huellas sobre las que constantemente recae, dejando expuesta la absolutez de tal separación. La trascendencia es la separación, la imposibilidad esencial que no me libra de la diferencia en tanto no-indiferencia. Tal como la necesidad de evasión proviene de la imposibilidad de decir, la trascendencia radica en la imposibilidad de pasar. La separación hace posible la tierra que habito, como producto del llamado que hago al otro. No hay retorno, hay imposibilidad de descanso. Cito para terminar a Lévinas:

\begin{abstract}
Como si yendo hacia el otro, me reencontrara y me implantara en la tierra, desde ahora natal, descargando de todo el peso de mi identidad. Tierra natal que no debe nada al arraigo, nada a la primera ocupación. Tierra natal que no debe nada al nacimiento. ¿Tierra natal o tierra prometida? ¿Expulsa ella a sus habitantes cuando olvidan el recorrido circular que les ha hecho familiar esta tierra, cuando olvidan su enrancia, que no era desarraigo sino despaganización? Habitar justificado por el movimiento hacia el otro (Lévinas, 2003).
\end{abstract}

El Hay podría finalmente, y a través de esa visión bíblica del exilio, pensarse como despaganización.

Sería necesario detenerse en la lectura de Celan y en la posibilidad que abre Lévinas a la poesía, a través de aquél, de alcanzar el decir ético. Para ello, hemos indicado el peregrinaje del poema desde el arte hasta el Hay, para devenir palabra en la tierra del otro. En su sobredimensión, en su experiencia cada vez más radical, el decir en general deviene pasivo, sin iniciativa, palabra prestada que me instala en esta noche. Podríamos decir entonces que se puede abrir la brecha para 
considerar con atención la poesía en relación con la ética, liberando su vecindad hacia una identidad que destruye el límite entre ambas.

\section{Referencias}

Celan, P. (2000). De umbral en umbral. Jesús Munárriz (tr.). Madrid: Hiperión.

Celan, P. (2002). Obras Completas. José Luis Reina Palazón (tr.). Madrid: Trotta.

Charles, D. (2005). Éthique et esthétique dans la pensée d'Emmanuel Lévinas. Espacethique, free.fr, 4 nov.

Gafamer, H.G. (1993). Poema y Diálogo. Barcelona: Gedisa.

Lévinas, E. (1967). Langage et proximité. En En découvrant l'existence avec Husserl et Heidegger. Paris: Vrin.

Lévinas, E. (1967). Sur Maurice Blanchot. Montpellier: Fata Morgana 1975.
Lévinas, E. (1967). (1987). De otro modo que ser. Antonio Pintor Ramos (tr.). Salamanca: Sígueme.

Lévinas, E. (1967). (1993). El humanismo del otro hombre. Graciano González R.Arnáiz (tr.). Madrid: Caparrós Editores.

Lévinas, E. (1967). (2000a). De la Evasión. Madrid: Arena Libros.

Lévinas, E. (1967). (2000b). De la existencia al existente. Patricio Peñalver (tr.). Madrid: Arena Libros.

Lévinas, E. (1967). (2003). Del ser al otro. En Noms Propres. Patricia Bonzo Moas (tr.). Chile: GEEL Universidad de Chile.

Lévinas, E. (1967). (2006). Los imprevistos de la historia. Tani Checchi (tr.). Salamanca: Sígueme.

Ricoeur, P. (1999). De otro modo. Barcelona: Anthropos. 